\title{
EDITORIAL
}

\section{The problem of problem selection}

For many busy managers with problems on all sldes, perhaps one of the hardest tasks is deciding which problems to work on first. In a Harvard Business Revlew article entitled "How senior managers think", Isenberg quotes one manager's description of this difficulty:

"I have to sort through so many issues at once.

There are ten times too many. I use a number of defence mechanisms to deal with this overload - I use delaying actions, I deny the existence of problems, or I put problems in a mental queue of sorts. This is an uncomfortable process for me. My office and responsibilities say I need to deal with all of these issues, so / create smoke or offer some grand theory as my only way to keep my own sanity. One of the frustrations is that I don't want to tell my people that their number one problems have lower priorities than they think they should get."

Decidlng the relative importance of problems might well be regarded as a key test of managerlal competence. Certainly, it is reasonable to suppose that a manager is judged not by the number of problems he or she solves, but by the impact of solutions on the performance of the manager's organizatlon.

A general example of thls "meta" problem is the widely recognised need for a proper balance of attentlon between strateglc and operating problems. As noted by Ansoff, such a balance Is difflcult to achleve. In most organizations, managers are concerned with a large number of recurring operatlng problems often generated automatically because of the need for continuing coordinatlon and control. In contrast, strategic issues are not self-regenerative and may make no automatic claims on top management attention. In many organizations, an increasing appreciation of the importance of strategic issues has led to the development of administrative structures which ensure that sufficient attention is paid to strategic issues. SImllarly, top management may change personnel and organizational structures from tlme to tlme to ensure that sufficient emphasis is placed on specified areas of declsion-maklng, be It finance, personnel, innovation, $R \& D$, acquisitlons, Internatlonal growth, etc. All the while, a major concern of top management is to avoid overload by establlshlng problem prloritles and by delegating as much as possible to lower managers. Nevertheless, the "meta" problem of how to determine which problems or Issues to work on Is a persistent concern at all levels of the organization, and frequently remains with each individual manager.

The management literature deals extenslvely with methodologies for handling particular classes of problem, such as strategic issues, but this meta-problem has received comparatlvely llttle attention. Yet it is a fundamental challenge for most managers. It is also a major concern to management consultants: partly because they have their own operating and strateglc concerns regarding their project portfolios, but also because much of their work involves influencing client managers regarding the level of attention that should be pald to partlcular issues.

An important prerequislte to selecting problems to work on is an effective approach to problem recognition. If problems are Interpreted as a performance gap between actual and desired performance, then thls amounts to a requirement for clear information about levels of performance expected and actual levels of attainment. There are substantlal dlfflcultles in meetlng these requirements adequately. Qulte apart from this, significant difflcultles remaln In determining problem priorities. It is not merely a matter of selectlng the problem that at first glance appears to be the worst. Kepner and Tregoe argue that the relative prlorlty accorded to problems should depend on answers to three Interrelated questions:

(1) How urgent Is the deviation from desired performance?

(2) What is the trend of the deviation and its potential for growth?

(3) How serlous is it?

The question of urgency concerns the level of time pressure behind a problem. Specific concerns here are how soon action must be taken, how long it will take to identify and implement a course of action, and how much time there is to make a decision. Urgency may be mitigated by the scope of interim, stop-gap action which might gain time for further analysis and postpone costly deployment of resources. Of course, urgency is reduced if problems and performance gaps are identified at an early stage. There is then more time to Identify and Implement possible courses of action, and usually a wider range of posslble responses is available. This means identifying issues at an early stage before performance gaps are very large and problems become more obvious. In a strategic context, thls translates into being responsive to what Ansoff calls "weak signals", when problem issues may be unclear and decisive responses difficult to formulate. In these clrcumstances, responses will be correspondingly unfocused, preferably emphasising flexibillty and robust courses of action, with refinement of response as information about an issue becomes more precise. 
Such considerations lead into the second question posed above, which asks about the trend of the deviation and its potential for growth. If no action is taken, will the problem persist and get worse? If so, at what point will it reach unacceptable proportions? Or alternatively, is it a problem that will flare up and then go away by itself, either because others will take action or because the same situation will not recur?

Third, but most importantly, priority ought to depend on the seriousness of the problem as expressed in terms of its potential impact on organizational performance. What are the effects going to be over a long period of time if the problem goes unchecked? Even low-level problems if allowed to persist may have an escalating impact on organizational activities. Significant considerations here are the extent to which the problem can spread to affect other parts of the organization, or is likely to generate further problems.

A further consideration is always the efficiency of the problem-solving process. With limited time and resources, a manager may give priority to those problems on which the fastest progress and the most important results can be achieved. This implies a potential bias towards problems on which the manager has a lot of information or relevant experience. In practice, the way in which managers rank problems may also be heavily influenced by how easy the problems are to solve. For example, Isenberg found that, on perceiving the existence of a problem, managers run a quick check to see if the problem is "solvable". Only if they find it is solvable do they invest further energy to understand its various ramifications and causes. Significantly, Isenberg also notes that identification of possible solutions may often precede and guide the process of problem definition. There are obvious dangers here, illustrated by hard-pressed line managers who exhibit a preference for dealing with operating problems and consequently ignore important strategic issues.

A final, common difficulty is that problems perceived as undesirable effects may have more than one contributing cause, and single causes may have a number of different effects. Many problems exist simultaneously, and issues are frequently interrelated. Attempting to deal with problems in some particular sequence may not be particularly efficient or effective. Isenberg notes that managers appear to form a mental network of problems which may be classified into broad issues. This allows a manager to exploit opportunities more flexibly and to use progress on one problem to achieve progress on other related issues.
What can be done to help managers with this problem of problem selection? What contributions can OR make?

Certainly, cognitive mapping and other problemstructuring techniques might be used more widely. Rather than applying them to tease out and understand composite issues in one particularly complex problem, such techniques could be useful on a more routine basis to help managers develop networks of the totality of problem issues they face - not so much to solve problems, but to develop priorities by clarifying relationships between issues. Such an exercise might be carried out by members of a consultancy to help target suitable areas for work.

OR expertise is often involved in the design of information systems to determine appropriate levels of performance and to measure actual levels of attainment. This kind of work can be influential in improving early recognition of problems, but this may only serve to increase difficulties with problem selection to the extent that it increases the number of performance deviations requiring management attention.

Finally, addressing the problem selection problem directly may help in persuading client managers to undertake specific pieces of work. Thus, client managers might be helped to choose a problem for attention by explicit consideration of:

- the relative urgency of the problem;

- the full effects of the problem, including an assessment of future trends if no action is taken; and

- possible stop-gap or incremental courses of action which might reduce the urgency of the problem.

Even where a consultancy does not actively have to seek work, these considerations may be useful in selecting projects on which to work and in allocating resources to projects. They may even be helpful in demonstrating the contribution made by the consultancy to organizational performance.

STEPHEN WARD

\section{For the interested reader}

Ansoff, H.I. (1984): Implanting Strategic Management, Prentice-Hall.

Isenberg, D.J. (1984): "How senior managers think", Harvard Business Review, November-December, pp. 81-90.

Kepner, C.H. and Tregoe, B.B. (1965): "Where to start", Ch. 4 in The Rational Manager - A Systematic Approach to Problem Solving and Decision Making, McGraw-Hill. 